\title{
Médiévales
}

Langues, Textes, Histoire

60 | printemps 2011

La fitna

\section{Anne LOMBARD-JOURDAN, Les Halles de Paris et leur quartier (1137-1969), Paris, éd. École nationale des chartes, 2009, 245 p. (Études et rencontres de l'École des chartes, 28)}

Hélène Noizet

\section{(2) OpenEdition}

Journals

Édition électronique

URL : https://journals.openedition.org/medievales/6233

DOI : $10.4000 /$ medievales. 6233

ISSN : 1777-5892

Éditeur

Presses universitaires de Vincennes

Édition imprimée

Date de publication : 30 juin 2011

Pagination : 212-213

ISBN : 978-2-84292-273-3

ISSN : 0751-2708

Référence électronique

Hélène Noizet, «Anne Lombard-Jourdan, Les Halles de Paris et leur quartier (1737-1969), Paris, éd. École nationale des chartes, 2009, 245 p. (Études et rencontres de l'École des chartes, 28) », Médiévales [En ligne], 60 I printemps 2011, mis en ligne le 30 août 2011, consulté le 23 avril 2022. URL : http:// journals.openedition.org/medievales/6233; DOI : https://doi.org/10.4000/medievales.6233

Ce document a été généré automatiquement le 23 avril 2022.

Tous droits réservés 


\title{
Anne LOMBARD-JOURDAN, Les Halles de Paris et leur quartier (1137-1969), Paris, éd. École nationale des chartes, 2009, 245 p. (Études et rencontres de l'École des chartes, 28)
}

\author{
Hélène Noizet
}

1 Il faut d'emblée souligner la particularité de cette publication et de son auteur, décédée deux semaines après la parution du présent ouvrage. En effet, ce livre correspond à la publication de la thèse soutenue par Anne Lombard-Jourdan à l'École des chartes en 1933. Ce travail initial, paru pour partie dans les synthèses déjà publiées du même auteur (Aux origines de Paris: la genèse de la rive droite jusqu'en 1223, Paris, CNRS, 1985), gagne ici à être rassemblé et précisément documenté. De plus, il a été enrichi par les publications et les méthodes scientifiques de la deuxième moitié $d u x^{e}$ siècle, parmi lesquelles le travail mené par l'équipe de F. Boudon sur les Halles, et notamment la fameuse publication architecturale de $1977^{1}$.

2 Anne Lombard-Jourdan décrit les réalités successives correspondant à l'appellation des «Halles » depuis la fin du XII jusqu'au milieu du $\mathrm{xx}^{\mathrm{e}}$ siècle, en reconstituant de la manière la plus exacte possible la topographie des lieux durant cette longue période. Elle développe sa synthèse, d'environ cent trente pages, en six chapitres, étudiant successivement, selon une approche à la fois chronologique et thématique: l'implantation initiale des Halles aux Champeaux, les aspects matériels et fonctionnels des halles médiévales, la répartition des bâtiments et des lieux de vente, les grandes étapes de l'histoire des Halles jusqu'au transfert à Rungis en 1969, et enfin une réflexion sur la durabilité de l'emplacement et de la fonction nourricière des Halles à Paris. En tant que médiéviste, elle accorde évidemment plus d'importance à la période médiévale, et notamment les $\mathrm{XIII}^{\mathrm{e}}$-XV $\mathrm{Xv}^{\mathrm{e}}$ siècles, en traquant dans les sources textuelles toutes les indications topographiques précises, susceptibles d'être spatialisées. Pour ce 
faire, elle sait croiser les sources écrites et iconographiques de périodes différentes, pour reconstituer notamment les limites des espaces propres au Moyen Âge central pour lequel on ne dispose évidemment pas de plan: ainsi en est-il du fossé des Champeaux, mentionné dans l'acte de 1137 entre l'évêque et le roi, qui est précisément localisé grâce à l'état des domaines du roi de 1728 (terrier de Louis XII). Les compétences d'archiviste-paléographe de l'auteur sont nettement perceptibles par l'édition de dix documents d'archives datant de 1264 à 1432, qui complètent de façon remarquable la synthèse.

3 La publication comporte deux index, dont un de toponymie parisienne qui rendra bien des services, et surtout cinq cartes, fort bien faites, permettant de visualiser concrètement l'évolution de ces lieux depuis le $\mathrm{XII}^{\mathrm{e}}$ siècle. L'ouvrage est également agrémenté d'un riche dossier iconographique de vingt-trois images, de 1183 à 1907, certaines en couleur. Il faut souligner la très grande qualité de ces annexes textuelles, planimétriques et iconographiques, qui révèlent un souci constant d'ancrer dans une documentation rigoureusement dépouillée les connaissances sur cette structure essentielle pour le ravitaillement de Paris. Il faut noter cependant que les références bibliographiques ne vont pas au-delà de 1991 et ne reflètent pas les riches et récents développements de l'histoire urbaine. On ne trouve pas ainsi de référence au Dictionarius de Jean de Garlande, pourtant récemment étudié ${ }^{2}$.

Ce travail pâtit parfois d'une approche un peu trop classique de l'évolution des formes spatiales et sociales et l'on n'est pas obligé d'adhérer à toutes les appréciations et formulations de l'analyse: faut-il vraiment parler des «causes de la longue immutabilité des Halles dans l'espace parisien» (p. 11), ou encore des "attitudes mentales» (p. 134) ? Aux expressions récurrentes de "force d'inertie», "pesanteur culturelle», «immobilisme si longuement durable», on peut préférer celles de la plasticité et de la réactualisation permanente de cette forme spatiale, qui s'est bien adaptée, dans la longue durée (couverture, libération de l'architecture adventice), aux diverses évolutions sociales.

5 Mais l'essentiel n'est pas là, et l'apport est réel. Cette synthèse donne de la chair et de la matière à la question d'histoire économique et sociale, centrale, de l'approvisionnement de Paris. Cette évocation du marché des Halles est à la fois détaillée et vivante, rigoureuse sur le plan de l'érudition et imagée. La remarquable persévérance d'A. Lombard-Jourdan, non seulement face au temps qui passe (trois quarts de siècle depuis le début du travail), et aussi face à des critiques - en partie justifiées -, mais parfois peu amènes de ses précédents travaux sur Paris ${ }^{3}$, encourage ainsi les historiens à reprendre l'histoire médiévale de Paris, notamment dans une perspective spatiale.

\section{NOTES}

1. F. BOUDON, A. CHASTEL, H. COUZY, F. HAMON, Système de l'architecture urbaine. Le quartier des Halles à Paris, 2 vol., Paris, 1977. 
2. F. LACHAUD, «La première description des métiers de Paris : le Dictionarius de Jean de Garlande (vers 1220-1230)», Histoire urbaine, 16 (2006), p. 91-114.

3. Par exemple, M. FLEURY, "L'enceinte dite du $\mathrm{X}^{\mathrm{e}}-\mathrm{XI} \mathrm{e}^{\mathrm{e}}$ siècle ", dans B. DE ANDIA éd., Les Enceintes de Paris, Paris, 2001, p. 46-49. 